\title{
Sociopolitical orientation of the youth community in Russia: the behavior modification approach to young people in the framework of higher education institutions
}

\author{
Viktoria Myasoyedova ${ }^{1, *}$ and Nataliya Lebedeva ${ }^{2}$ \\ ${ }^{1}$ Institute of Systems of Economics and International Law Management, Moscow, Russia \\ ${ }^{2}$ Moscow State University of Technologies and Management named after K. G. Razumovskiy, Moscow, Russia
}

\begin{abstract}
The paper is an attempt to analyze the state of the sociopolitical orientation of young people in Russia which is caused by the political process launched in the course of reforms. Some recommendations on the behavior modification in the framework of the social institution of elite cadres training - higher school - are also presented. The authors of the article substantiate the following idea: while studying at a higher education institution, the individual must be able to acquire the necessary expertise that allows them to take up active life, civic, and political positions. Examples of such competencies are: general legal literacy; the ability to critically evaluate information, etc. Some particular conditions for the formation of young people's outlook on life, the formation of their sociocultural and cultural political positions that should be implemented in higher education through educational, scientific, and innovative leisure activities are presented in the article; the recommendations for their formation in higher education institutions are also given.
\end{abstract}

\section{Introduction}

The article is an attempt to analyze the state of the sociopolitical orientation of young people in Russia which is caused by the political processes launched in the course of reforms. Some recommendations on the modification of young people's behavior in the framework of the key social institution of elite cadres training - higher school - are also presented. The analysis is based on the data of the All-Russia sociological surveys, collected over 10 years, illustrating the attitude of the population to the political situation, the government, and the social processes in the country.

At the beginning of the 1990s, from the transition to democracy, we expected, first of all, an increase in economic well-being, not a change in the principles of the political system. Having realised that the democracy promised by the political elite cannot come in one day, many people got disappointed in the feasibility of such a political system. Economic hardship, growing corruption, the rise of the oligarchs and political scandals discouraged the population from the commitment to democratic principles even more [1]. While most of the youth support the current political regime, one can observe noticeable growth of apathy, lack of interest and skepticism about both the political processes and the political elites [1]. Modern researchers describe the attitude of most young people to the political system as the support of Vladimir Putin's policy; at the same time they are skeptical about the functioning of the political system. Thus, a significant part of the younger generation $(67,8 \%)$ said that they have no ability to influence the policy of the state, and they cannot defend their interests either $(56,5 \%)$ [2].

The electoral activity of the Russian youth is also quite low. Even the representatives of the youth community, who are university students, are not politically active, and $75.3 \%$ of them do not see themselves as full participants in the political system [3].

The analysis of the mood, the priorities and the existing sociopolitical orientations shows that today's young people as a whole tend to positively evaluate their life in the country, in contrast to other age groups. So, $45 \%$ of young people positively evaluate today's life in Russia, at the same time, this figure is $35 \%$ among the older generation [4]. A gap like this can be observed in the survey of 2011. Life as a whole quite satisfies $22 \%$ of young people, mostly satisfies $43 \%$ of young people. At the same time, these figures are $13.3 \%$ and $28.3 \%$ respectively for the older population. [5]. Still, this gap cannot be regarded as an indicator of the value heterogeneity of the society. The fact that young people are more optimistic in their outlook on life correlates, in the first place, with the features of their age, not with good political conditions. In the poll by VTsIOM (Russian Public Opinion Research Center), in 2013, the younger generation places 'youth provision' first ("Which of the following issues do you consider the most important ones for yourself"), while the generation of over 24 ranks 'inflation, the growth of goods and

\footnotetext{
Corresponding author: vika20002004@mail.ru
} 
services prices' number one. The youth ranks this problem number two.

'Health Service issues' are ranked number two by the older generation while the same problem takes only the ninth place in the ranking of the youth which is quite natural (most young people haven't experienced health problems yet). The same percentage of the respondents of the younger and older generations believe that "standard of living" is an important issue for them (third and fourth place, respectively) [6].

The orientations of the youth are not so optimistic with respect to the present political situation in the country. Only $39 \%$ of young people assess the political situation as 'right', $40 \%$ still believe that things in Russia as a whole go in the 'wrong' direction [5].

All-Russian sociological opinion polls form the basis for the analysis. The surveys have been conducted for 10 years and represent the attitude of the people to the political situation, the government and authorities, and social processes in the country.

The analysis of the sociopolitical orientation of today's young Russians allows us to arrive at the following conclusions:

- of young Russians tend to perceive the state as a paternalistic model; they view the state as justice, reliance, and are ready to sacrifice part of their freedom in exchange for social support;

- of young Russians support democracy as a state of numerous freedoms, various social guarantees, and personal everyday adaptation to the new life conditions at the same time;

- of young Russians do not trust the experience of the older generation, do not accept the Soviet experience and do not have any clear guidelines, code of conduct or spiritual goals in their activity;

- at this conjuncture, it is essential to work out some approaches to the modification of the behaviour of young Russians who are potentially to become the intellectual and political elite of the country; forming their sociopolitical guidelines and activating their political and civil positions are also highly needed.

\section{Analysis and discussion}

The assessment of the state of the contemporary political situation - not the direction itself - is equable in general, regardless of generational identity. Less than $10 \%$ in both age groups evaluate the political situation in Russia as being good. At the same time, the majority $(46.1 \%$ and $44.2 \%$ respectively) evaluate the political situation as tense.

More than $52 \%$ of respondents aged 18-24 believe that the political life in Russia can represent the development of democracy, while $11 \%$ assess the political life as the emergence of authoritarianism and dictatorship, $6 \%$ - as growth of chaos and anarchy, and a significant proportion of respondents (about 28\%) found it difficult to estimate the development trends of the political life in the country. Thus, the development of democracy was mentioned by $39 \%$ of respondents over 24 , more than $12 \%$ of them believe that the political life is moving in the direction of authoritarianism and dictatorship. The increase of anarchy is observed by $17 \%$ of respondents, and about $23 \%$ of respondents found it difficult to answer [7].

The proportion of young people who believe that there is a democratic society in Russia, is $46 \%$, while only $33 \%$ of the respondents representing the older generation share the similar point of view [7]. Thus, the assessment of satisfaction with the development of democracy in Russia practically does not vary between different age groups. $25 \%$ of respondents are completely satisfied, $28 \%$ - rather satisfied. The same number of respondents among the youth and the adult generation are fully prepared to support the slogan of "democratic transformation of Russia" (29\% and 33\% respectively). At the same time, practically the same proportions among the respondents are not ready to support a slogan with similar content (11\% and $7 \%$ respectively) [8].

Dreams of hard power: the proportion of respondents who dream of a strong leader who will bring order to the country is the same for the younger and older generation and is quite significant (56.6\% and $58.5 \%$ respectively). The paradox is that, when answering the question about the necessity of supporting democratic institutions, rather than the individual dictatorship, most of the respondents, both of the younger and older generation are in favor of democratic institutions $(37.1 \%$ and $38.5 \%$ respectively) or found it difficult to answer (44.2 and $42.6 \%$ respectively). This paradox can be caused by the negative connotation of the term 'dictatorship', which is used in the text of the question.

Orientations on the 'input' requirements for what a state policy towards the media should be [9] differ according to the age group. Thus, $23 \%$ of young people are for the complete freedom of information of all the media, as well as the independence of the media from the state. It should be taken into account that the proportion of the representatives of the older generation who share the same opinion is only $16 \%$. Most young people support the need for setting some moral restrictions on the leading media (mainly in relation to violence and eroticism, etc.).

Assessing the current state of the economy. $61 \%$ of young people assess the current economic situation in Russia as average, the mature generation is more skeptical: only $49 \%$ share this view. [10] At the same time, more than $34 \%$ among the respondents representing the older generation believe that the economic situation in Russia is poor, while such an assessment is shared by only $20 \%$ of respondents among young people.

Despite the fact that, quite naturally, the financial situation is better among the older generation, the majority of young people still believe that they themselves are responsible for material wealth $(70 \%$ of today's young people share the point of view 'my financial situation now and in the future depends on me - in the first place'). If we have a look at the older generation, we will see that $49,8 \%$ of the respondents also view themselves as those who are responsible for their own material well-being; still, $50,1 \%$ believe that the economic situation in the country, rather than 
individual's actions, affects the prosperity of the individual [4].

Orientations that are relative to the economic policy are practically identical both among young people and the older generation. $23 \%$ and $21 \%$ respectively are satisfied with the conduct of the economic policy of the current government, while $39 \%$ and $41 \%$ respectively are 'partly satisfied but partly no' [11].

$21 \%$ of young people believe that Russia will become a prosperous country in the next $5-10$ years; $47 \%$ believe that it will happen in 10-20 years, while the older generation's estimation is more pessimistic. Their score goes like this: $11 \%$ expect economic prosperity in the next $5-10$ years, $31 \%$ - in the next $10-20$ years, while $55 \%$ do not rely on the possibility of such growth during the lifetime of their generation [4].

In 2013, about $40 \%$ of young people are 'mostly satisfied' with the foreign policy, while among the older population, the similar view is shared by a smaller proportion of respondents $(33 \%)$. The foreign policy of the current authorities is defined as 'quite satisfying' by $33 \%$ of the respondents over 24 and by about $33 \%$ of the respondents aged 18-24 [12]. $20 \%$ of the older generation and only $10 \%$ of young people fully support the government's performance; $23,3 \%$ of the older generation and more than $30 \%$ of young people are more likely not to approve it.

The evaluation of the social policy of the state. In 2013, the majority of the population marked 'the social policies of the current authorities' [13] as 'partly satisfying, partly no' (42\% of young people and $38 \%$ of the respondents over 24). $20.5 \%$ of the older generation and $22 \%$ of the younger generation are 'mostly satisfied', as well as $20 \%$ and $26 \%$ are 'mostly not satisfied'. $7 \%$ and $4 \%$ respectively are quite satisfied.

The orientations of young people in terms of the 'current government' are quite close to those of 24 yearolds. According to the results of the survey of the year 2013 , $46 \%$ of young people and $41.5 \%$ of the older generation support the current government, believing that 'in general, their policy is right; they manage to cope with the difficulties'. At the same time, $38 \%$ of young people share the following point: 'I still tolerate the current government, but it makes a lot of mistakes, their policy is not always true'. The belief that the current government is 'riddled with corruption' and it is becoming impossible to tolerate this state of affairs is shared by a much smaller percentage of citizens (12\% of the youth and $14 \%$ of those who are older) [14].

Political identification. The same proportion of the respondents among both young people and the older generation consider themselves to be patriots: $69.6 \%$ and $72.4 \%$ respectively [7].

Young people aged 18-24 and those who are over 24 view the idea that can unite the nation differently. According to the opinion of young people and the older generation, stability is the best way of uniting the nation. 'Law and order' are marked number two, 'strong superpower' is ranked number three, 'equality and justice' - number four. What concerns the fifth position, here young people place 'progress and development', while the older generation place 'social protection'.
'Wealth and prosperity' is marked number six by both age groups [9].

More than $24 \%$ of young people believe that the system with one strong ruling party is the best for Russia, $50 \%$ support the system with two or three big parties, $8 \%$ of young people believe that it is necessary to have many small parties, less than $5 \%$ state that there is no need for political parties [7].

The opinion of today's young people about what ideology suits the Russian people best is different from the similar view of the older population. Thus, $34 \%$ of the respondents aged 1824 view democracy as a suitable ideology, while the proportion of the older generation, who share this view, is only $26 \%$. At the same time, $20 \%$ of the respondents over 24 view socialism as the most suitable ideology, while only $11 \%$ of young people share this view. The proportion of those people who do not accept giving or receiving bribes at all is smaller among young people than among the older generation (34\% and $47 \%$ respectively) [4].

Political competence. In 2007, the proportion of young people and the older generation taking part in political activity was practically equal: $2,3 \%$ and $1,4 \%$ respectively. The percentage of young people who are not interested in politics at all is much higher than among the older generation $(48,7 \%$ and $28,9 \%$ respectively). In 2007, only $13,9 \%$ of younger respondents followed the information about the political events - compared to the $25 \%$ of the representatives of the older generation. [See: Young People in New Russia..., 2007] $45,6 \%$ and $25 \%$ of young people respectively are not quite interested or are not interested at all in politics. What concerns the older generation, only $35 \%$ of the respondents are not quite interested in politics. $31 \%$ of the older generation and 21 of young people are interested in politics [7].

At the same time, the fraction of young people who believe that they will go to the elections to the State Duma was practically equal to the corresponding fraction among the older population; they constitute $21 \%$ and $25 \%$ respectively [15]. If elections were held next Sunday, $9 \%$ of the youth and $10 \%$ of the older generation would not go to elect the president [5].

Political effectiveness. $85 \%$ of the population older than 24 do not want to get access to power; the similar rate among young people in the 2000s is much lower$64 \%$. This gap, most likely, can be explained not only by the uncertainty of the life of young people, but also by the growing popularity of youth political movements [4].

Orientation to the rights and freedoms of the individual. The majority of both young respondents and the representatives of the older generation believe that their right to participate in society and state management is implemented satisfactorily $(27 \%$ and $28 \%$ respectively). At the same time, $25 \%$ and $24 \%$ find it difficult to answer this question, $20 \%$ and $19 \%$ respectively believe that their rights are implemented poorly. $20 \%$ of respondents among older people and $16 \%$ of young people believe that their rights are not being implemented at all.

The proportion of people who are ready to take part in the mass protest both among the youth and the older 
generation is the same ( $20 \%$ and $17 \%$ respectively). $73 \%$ and $76 \%$ responded that it is most likely that they will not take part in mass protests [5].

Participation in meetings in December 2011. Among the ordinary participants at the meetings at Chistye Prudy and Bolotnaya, young people prevailed, while at Sakharov Prospekt and Yakimanka middle-aged people prevailed - according to the surveys by the Levada Center [16]. The participants of the meetings at Chistye Prudy and Bolotnaya were mobilized mainly through social networks, which explains the fact that young people prevailed there. The infringement of such civil rights and freedoms as 'freedom of speech, conscience, freedom to express one's thoughts' [17] will make 50\% of respondents protest; $38 \%$ will not protest (aged over 24) 44 of young people will protest and $41 \%$ will not.

The modern Russian and foreign youth. In addition to the correlation of the political orientations of the modern Russian youth to the orientations of the older generation and the young generation of the 1990s, it is quite logical to make a comparative analysis of the political preferences of young people in a number of foreign countries - before summing up the findings.

A number of developed countries was chosen from the database World Value Survey [18]; their features were compared with those in Russia: France; Great Britain; The USA; Finland.

Orientation to a strong leader. 'Having a strong leader in the country - it's pretty good': the proportion of young people who share the similar point of view is the highest in Russia, while the representatives of the youth of developed countries are less likely to share similar paternalistic attitudes.

The same is with the orientations 'Having a democratic system is very good'. Among the Russian youth the proportion of the respondents who share this view is the smallest. For example, in France this figure will be higher by more than $20 \%$. All this indicates the absence of the system of Western democratic values in the Russian society; for young Russian people, Western democratic values are less important than the traditional Russian ones.

Thus, having the political orientations of the modern Russian youth analyzed, we can arrive at the following conclusions. The analysis of the sociopolitical orientations of young people, as a narrow slice of the political preferences of the whole society, allows us to see the potential for the development of the institution of youth political leaders in Russia in general.

Taking into account the relatively short period of existence of the new Russia, the analysis of the dynamics of development of the institution of youth political leaders within the open political system of the federal state enables young people to become actors of the political processes. The focus on the present, not trusting the experience of the older generation, the rejection of the Soviet experience should be added here. The actualization of the main areas of youth work takes place in the atmosphere of not trusting the political institutions; still, there exists a paternalistic focus on the state - state as support - state as fairness, and the willingness to sacrifice part of freedom for the sake of social support.

It is also necessary to focus on the following conclusions as well:

- Anti-European, anti-Western, anti-liberal identity, identity through negation.

- The orientations of the youth to democracy as a society of various liberties and social guarantees.

- The orientation of the youth to the personal adaptation to the new life conditions.

- The lack of clear guidelines, code of conduct among the younger generation.

Analyzing the data of the sociological research on the political preferences of the youth, we should remember that the critical assessment of the situation, under the conditions of difficult external environment, and the adoption of appropriate decisions related to their political choice and future development of the country, rests on the shoulders of the younger generation.

In this context, the formation of an active and intellectually developed person, a representative of the youth community, who has a particular sociopolitical orientation and takes up an active political position is the absolutely important factor of Russia's competitiveness. That's why the development of effective approaches to modify the behavior of young people as the potential intellectual and political elite of the country, as well as the formation of their sociopolitical orientations, is a particularly urgent problem of the modern society.

As a consequence, the role of the education system, higher school in particular, as the subject of forming a completely innovative and intellectually active individual, able not only to perceive critically the current reality, but also to respond adequately within the unstable political and geopolitical environments. High school becomes an institution in which an individual, a representative of the youth community, should be able to acquire the necessary expertise, that allows them to navigate freely not only in the chosen professional field but in the sociopolitical environment as well; to take up an active personal, civil, and political position.

The given expertise is a combination of the results of the deliberate action on the individual in high school, the purpose of which is to create electoral-active citizens capable of critical perceiving and analyzing the political situation in the country, as well as sociopolitical processes and phenomena, and integrating into the social and political space in order to participate in strategically important state decisions and the implement their rights and freedoms guaranteed by the Constitution of the Russian Federation.

The examples of the expertise can be found here:

- basic knowledge of the country's state structure and key regulatory documents (the Constitution of the Russian Federation);

- general legal literacy;

- knowledge of the basic principles of the protection of their rights and interests;

- the ability to critically evaluate information obtained through the media, the Internet and other sources; 
- understanding of the role and place of the individual in civil, social and political communities;

- clear socio-acceptable life guidelines, code of conduct and intangible assets.

It is necessary to form the given expertise during the whole period of studying, regardless of specialty of training or form of education.

The processes of outlook formation, the formation of sociocultural and cultural-political positions also play the key role in the formation of the politically literate individual. They can be carried out in high school through educational, scientific and innovative leisure activities. In order to perform it successfully, some special conditions should be provided. They will allow to:

- to get up-to-date information and learn how to perceive it critically;

- to set the priorities of taking up an active part in the life of the civil society and making one's political choice;

- to involve youth communities in sociopolitical processes;

- to form the certain outlook;

- to form the understanding of the relationship among the political situation, the level of life of the population and one's own well-being and prosperity;

- to use the information and communication space effectively in order to implement the initiatives of citizens.

\section{Conclusions}

Thus, the formation of the youth community, that is ready to take up an active part in the political life of the country; as well as the development of the institution of youth political leaders in Russia, has the significant potential. Still, it can be hampered by the lack of clear sociopolitical orientations, the lack of trust towards the political institutions among young people, the low level of political and civic engagement activity. One of the solutions to these problems can be the modification of the behavior of young people in the framework of higher school -the social institution of cadres training.

This work is funding the Ministry of Education and Science of the Russian Federation (project number 1013
"Theoretical and methodological foundations of modeling and forecasting of innovative development of the university and its effective participation in the development of high-tech sectors of the economy on the basis of the formation of the cluster virtual environment interaction").

\section{References}

1. D. Daflon, Data. Analysis. Discussions, 5, 24 (2008)

2. M.K. Gorshkov, F.E. Sheregi, Historical and theoretical and methodological background studies of youth in Russia, In Russia and China: the young people of the 21st century, p. 7-32 (Moscow, 2014)

3. I.V. Barynin, Sociodynamics, 6, 1-19 (2015)

4. http://sophist.hse.ru/db/oprview.shtml?ID_S=2281\& $\mathrm{T}=\mathrm{m}$

5. http://sophist.hse.ru/db/oprview.shtml?ID_S=2515\& $\mathrm{T}=\mathrm{m}$

6. http://wciom.ru/zh/print_q.php?s_id=890\&q_id=618 $51 \&$ date $=27.01 .2013$

7. http://sophist.hse.ru/db/oprview.shtml?ID_S=2300\& $\mathrm{T}=\mathrm{m}$

8. http://wciom.ru/zh/print_q.php?s_id=495\&q_id=364 $47 \&$ date $=20.11 .1995$

9. http://wciom.ru/zh/print_q.php?s_id=706\&q_id=510 $52 \&$ date $=09.01 .2011$

10. http://sophist.hse.ru/db/oprview.shtml?ID_S=2515\& $\mathrm{T}=\mathrm{m}$

11. http://wciom.ru/zh/print_q.php?s_id=890\&q_id=618 $37 \&$ date $=27.01 .2013$

12. 2013.URL:http://wciom.ru/zh/print_q.php?s_id=890 $\& q \_i d=61839 \&$ date $=27.01 .2013$

13. http://wciom.ru/zh/print_q.php?s_id=890\&q_id=618 $38 \&$ date $=27.01 .2013$

14. URL:http://wciom.ru/zh/print_q.php?s_id=890\&q_i $\mathrm{d}=61866 \&$ date $=27.01 .2013$

15. http://sophist.hse.ru/db/oprview.shtml?ID_S=2513\& $\mathrm{T}=\mathrm{m}$

16. D. Volkov, Journal of Public Opinion, 2, 74 (2012)

17. http://www.worldvaluessurvey.org

18. http://wciom.ru/zh/print_q.php?s_id=718\&q_id=519 $85 \&$ date $=27.03 .2011$ 